142

one hospital, and the interest or notoriety of a new development. The posts are in one of the major teaching hospitals of the city.

Nine doctors have completed their pre-registration posts and a further six are at present completing their year. Of the nine, five have taken up vocational traineeships in general practice and the remaining four propose to continue in psychiatry. Two of them have passed the Preliminary Test of the Membership Examination and two have spent time in other departments of medicine before coming into psychiatry.

The general medicine component is seen as the most busy unit, with little time to spend with patients or on educational activities. The surgical component is less busy because of the more senior doctors who want to 'get their hands on the knife', so that much of the work is routine clerking and blood taking. The psychiatric component gives considerable individual responsibility with selected patients, but with ample access both to more senior doctors and to other professions-nurses, occupational therapists, psychologists and social workers working in the unit. There is unresolved discussion about the preferable order of the three components; each trio has their own choice of the order in which they work. The only comment was by one doctor who started with psychiatry and then was up until $2.00 \mathrm{am}$ taking psychiatric histories on medical patients on transfer to the general medical section.

Each house officer is on call for the relevant unit. In medicine and surgery there are two on each firm, one doing four months and the other six months so that there is some overlap and cover for holiday periods. In psychiatry the one-in-four rota is operated to give the house officer an opportunity of being on-call covered by the duty registrar. On the remaining three days, the registrar has no junior to do the work, or, of course, to cover.

Judging by the number of applicants for the posts, the setting up of a second rotation and the general comments of those who have participated, these are seen as interesting, innovative and valuable educational posts giving a wider range of experience than normally available to a pre-registration house officer. Suggestions that newly qualified house officers are too immature to work in a psychiatric setting seem unjustified. These newly qualified doctors have the benefit of working in a multidisciplinary team with contributions from a range of professions and gain experience which will stand them in good stead in whatever branch of medicine they subsequently work.

C. P. Seager

Northern General Hospital Sheffield

\section{Psychotherapy and drug company promotion Dear Sirs}

Psychotherapy cannot rely on the same sources of funds and support as can the rest of psychiatry and medicine given their organic basis. Research funding and drug company promotion are not easily linked with psychotherapeutic matters. On top of this, psychotherapy often faces critical attacks to which
THE ROYAL COLLEGE OF PSYCHIATRISTS, VOL 9, JULY 1985 there are inherently no easy answers.

It might therefore seem to be a welcome addition to the freely distributed mass of drug promotional literature that comes through our letter boxes to find a 'newspaper' entitled Psychotherapeutic Advances. Unfortunately, this turns out to be the most insidious attack yet! Sponsored by Bristol-Myers, and completely free of advertisements, the paper contains journalistic articles on a number of interestig subjects, all of it with a medical scientific flavour, despite the vaguely psychotherapeutic aspects.

But scattered throughout the articles are repeated references to drug treatment, as if it was quite unremarkable to be mixing the two methods together without consideration of how they can be made compatible or be found incompatible. A choice example is: 'In psychotherapy, Buspirone should be considered in the treatment of anxiety disorders, particularly those that respond to benzodiazepines...' Thus, the impression is given that 'psychotherapy' is just a slightly glorified form of psychopharmacology.

Still with no easy rejoinder to this kind of propaganda, I despair.

\section{Child and Family Clinic \\ 49 Airbles Road \\ Motherwell, Lanarks}

Nick ChILd

(We invited Bristol-Myers Pharmaceuticals to reply to Dr Child's letter-Eds.)

\section{Dear Sirs}

Psychotherapeutic Advances includes articles on both drug and non-drug modes of therapy and is intended to provide information pertinent to those dealing with mental disorders. It is to be regretted that a publication which attempts to span several disciplines should draw such criticism from Dr Child.

Bristol-Myers, PMS

B. M. GUYER

Langley, Berks.

\section{A chat with the other side}

\section{Dear Sirs}

I thought that the following might be of interest to Bulletin readers.

Bulawayo ('place of slaughter') is the second major city in Zimbabwe and one of the most beautiful sights on earth. Working in the old psychiatric hospital on the outskirts of town. I quickly discovered that many patients who came to me had either seen the nganga ('witch doctor') beforehand or would hasten to see him when they were through with me. The Government, as a deliberate policy, was according traditional health care recognition and the right to practise alongside 'Western' medicine. I once visited one of these 'doctors', as I felt it would be educative to see traditional health care from the inside.

He was a little slip of a man in a rather shabby white 